\title{
A short total synthesis of parvaquone
}

\author{
Cesar R. Solorio-Alvarado, Cristina G. Rodríguez-Cendejas, and Eduardo Peña-Cabrera* \\ Facultad de Química. Universidad de Guanajuato. Col. Noria Alta S/N. Guanajuato, GTO \\ Mexico 36050 \\ E-mail: eduardop@quijote.ugto.mx
}

(received 23 Sep 03; accepted 12 Dec 03; published on the web 13 Dec 03)

\begin{abstract}
Parvaquone 1, a hydroxylated naphthoquinone with antiviral properties, was prepared in 26\% overall yield in a straightforward manner starting from diisopropylsquarate 3 . The key features of the synthesis include addition of commercial cyclohexylmagnesium chloride to $\mathbf{3}$, followed by acid-catalyzed rearrangement to furnish the cyclohexyl-substituted isopropylsquarate 2 . Further addition of phenyllithium to 2 , thermal cyclization and deprotection with $\mathrm{BBr}_{3}$ gave $\mathbf{1}$.
\end{abstract}

Keywords: Parvaquone, squaric acid ester

\section{Introduction}

Hydroxylated quinones often possess interesting biological activity and there is an increasing interest to develop new and efficient ways to prepare them. ${ }^{1}$ Examples of biologically active hydroxy-substituted quinones range from those of relatively simple structure, i.e. Echinochrome $\mathrm{A},{ }^{2}$ to examples of high complexity, i.e. conocurvone. ${ }^{3}$<smiles>CCC1=C(O)C(=O)c2c(O)c(O)c(O)c(O)c2C1=O</smiles>

echinochrome A<smiles>CC(C)=CCC[C@@]1(C)C=Cc2c(ccc3c2C(=O)C(O)=C(C2=C(C4=C(O)C(=O)c5c(ccc6c5C=C[C@@](C)(CCC=C(C)C)O6)C4=O)C(=O)c4c(ccc5c4C=C[C@](C)(CCC=C(C)C)O5)C2=O)C3=O)O1</smiles>

conocurvone 
Parvaquone 1, is another example of a hydroxyquinone that displays interesting biological properties. It has been used against theileria parva, a microscopic parasite that causes East Coast Fever (theileriosis). ${ }^{4}$ East Coast fever (ECF), a form of bovine theileriosis, is a ticktransmitted protozoal disease of cattle characterized by high fever and lymphadenopathy. The disease causes high mortalities in breeds nonindigenous to the endemic areas, and is confined to eastern, central, and parts of southern Africa.

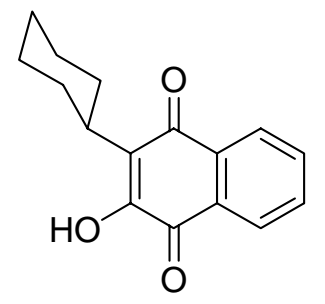

\section{parvaquone (1)}

We wish to report the total synthesis of $\mathbf{1}$, based on the chemistry of squaric acid esters developed by Liebeskind, Moore and others. ${ }^{5}$

\section{Results and Discussion}

Despite the fact that Kerr et al. ${ }^{4}$ have reported an efficient chromium carbene-based synthesis of parvaquone, it was considered that a chromium-free alternative was worth pursuing. Thus, the preparation of 1 was envisioned as illustrated in Figure 1.

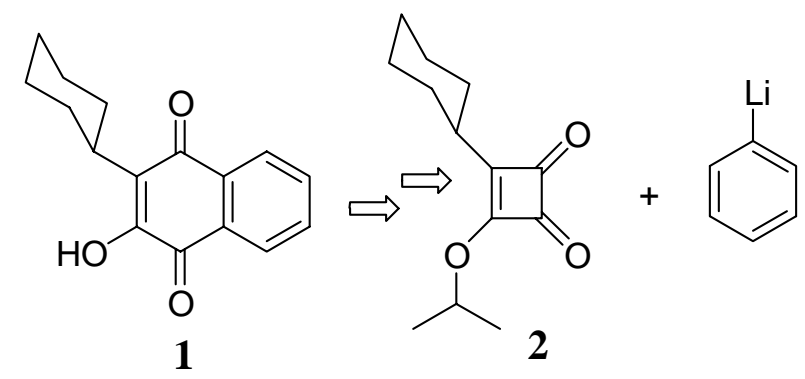

Figure 1. Retrosynthetic analysis of parvaquone.

The synthesis was begun with the addition of commercially available cyclohexylmagnesium chloride to diisopropylsquarate $3^{6}$ at $-78{ }^{\circ} \mathrm{C}$ in THF. Quenching the reaction mixture at low temperature to give the corresponding 1,2-adduct followed by acid-catalyzed rearrangement, produced the cyclohexyl-substituted dione 2 in $68 \%$ overall yield (eq. 1). ${ }^{7}$ 


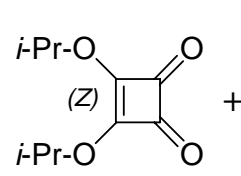

3<smiles>ClC1CCCCC1</smiles>

(1) $-78{ }^{\circ} \mathrm{C} / \mathrm{THF}$

(2) aq. $\mathrm{NH}_{4} \mathrm{Cl} /-78{ }^{\circ} \mathrm{C}$

(3) cat. $\mathrm{H}^{+} / \mathrm{CH}_{2} \mathrm{Cl}_{2} / 25^{\circ} \mathrm{C}$

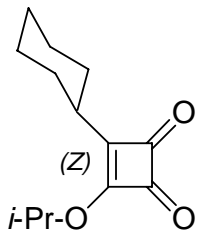

The efficiency of the previous reaction was improved when the protocol introduced by Moore was used, i. e., low temperature trifluoroacetic anhydride (TFAA) quench of the 1,2adduct gave 2 in $93 \%$ yield (eq. 2). ${ }^{8}$<smiles>CC(C)Oc1c(O[18F])c(=O)c1=O</smiles>

3

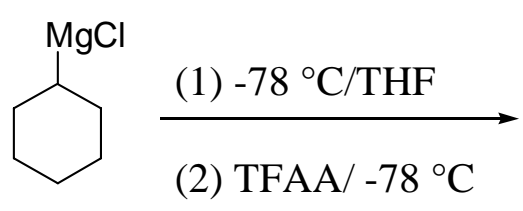

(2) TFAA $/-78^{\circ} \mathrm{C}$

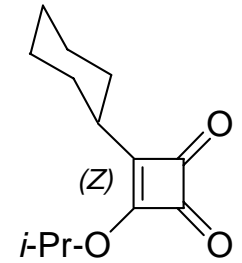

2, $93 \%$

Nucleophilic addition of phenyllithium to the more electrophilic carbonyl group of 2 , followed by aqueous quench furnished alcohol $\mathbf{4}$ in modest yield (eq.3).

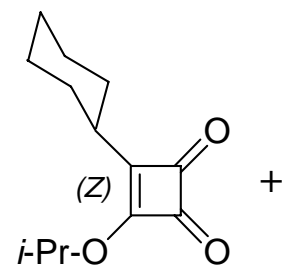

2
(1) $-78^{\circ} \mathrm{C} / \mathrm{THF}$

(2) aq. $\mathrm{NH}_{4} \mathrm{Cl} /-78{ }^{\circ} \mathrm{C}$

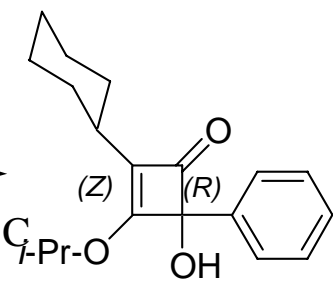

4, $44 \%$

Then, thermolysis of $4\left(135^{\circ} \mathrm{C}, 45 \mathrm{~min}\right)$ generated hydroquinone $\mathbf{5}$, which on exposure to air, immediately oxidized to naphthoquinone 6 in 78\% yield (Scheme 1).

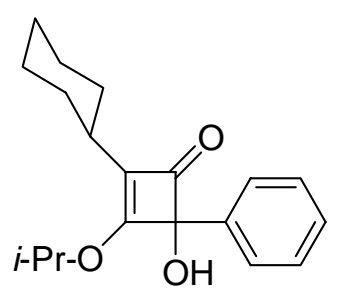

4

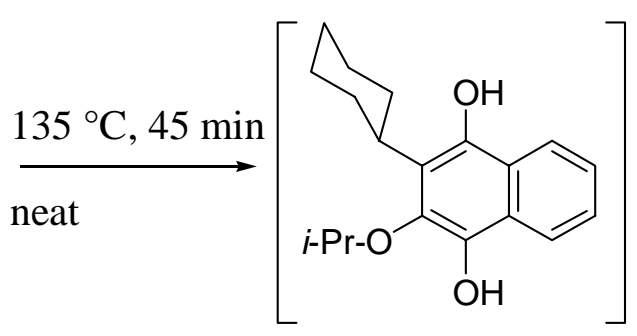

5<smiles>CC(C)OC1=C(C2CCCC2)C(=O)c2ccccc2C1=O</smiles>

6, 77\% from 4

Scheme 1. Synthesis of 6. 
Finally, parvaquone 1 was synthesized by treating 6 with an excess of $\mathrm{BBr}_{3}$ to yield a yellow crystalline solid with identical spectral properties as those reported previously (eq. 4). ${ }^{4}$

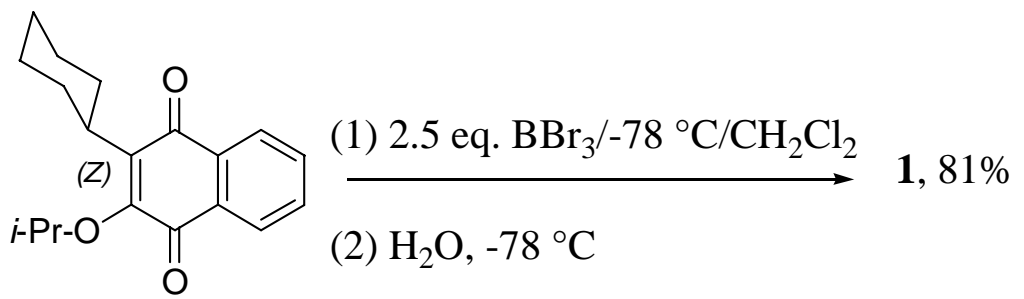

6

In conclusion, a straightforward synthesis of parvaquone was developed with a $26 \%$ overall yield. Most of the steps in the synthetic sequence are efficient and the starting materials are either commercially available or readily prepared. Moreover, this method offers the possibility for the preparation of a host of parvaquone analogues by the addition of aryllithium derivatives with different substitution patterns.

\section{Experimental Section}

General Procedures. ${ }^{1} \mathrm{H}$ NMR spectra were recorded on a Varian Gemini 200 (200 MHz) spectrometer in deuteriochloroform $\left(\mathrm{CDCl}_{3}\right)$ with either tetramethylsilane (TMS) $(0.0 \mathrm{ppm})$ or chloroform (7.26 ppm) as internal reference unless otherwise indicated. Data are reported in the following order: chemical shift in $\operatorname{ppm}(\delta)$, multiplicities (br (broadened), s (singlet), d (doublet), t (triplet), q (quartet), sex (sextet), hep (heptet), m (multiplet), exch (exchangeable), app (apparent)), coupling constants, $J$, are reported $(\mathrm{Hz})$, and integration. Infrared spectra were recorded on a Perkin-Elmer FTIR 1600 series spectrophotometer. Peaks are reported $\left(\mathrm{cm}^{-1}\right)$ with the following relative intensities: s (strong, 67-100\%), m (medium 40-67\%), and w (weak 20-40\%).

Analytical thin-layer chromatography was performed on Merck silica gel plates with F-254 indicator. Acid-pretreated silica gel plates were used to monitor the final deprotection of 2 . Visualization was accomplished by UV-light, iodine, or $p$-anisaldehyde solution. Medium pressure liquid chromatography (MPLC) was performed as described by Baeckström et al. ${ }^{9}$ using gradient solutions with the indicated solvent systems. THF was dried over sodium and stored over activated $4 \AA$ molecular sieves. All reactions were performed under a dry $\mathrm{N}_{2}$ atmosphere in oven- and or flame-dried glassware.

Commercial chemicals. The following materials were obtained from commercial sources: $\mathrm{C}_{6} \mathrm{H}_{11} \mathrm{MgCl}$, PhLi, TFAA, and $\mathrm{BBr}_{3}$. 


\section{Experimental procedures}

3-Cyclohexyl-4-isopropoxycyclobuten-1,2-dione (2). Cyclohexylmagnesium chloride (26 mmol of a $2 \mathrm{M}$ ether solution) was added via syringe to a cold $\left(-78{ }^{\circ} \mathrm{C}\right) \mathrm{THF}(10 \mathrm{~mL})$ solution of diisopropoxysquarate 3 (4.0 g, $20.2 \mathrm{mmol}, 1.3$ equiv.). After $20 \mathrm{~min}$., TFAA (3.3 mL, 20.2 mmol) was added at $-78{ }^{\circ} \mathrm{C}$ via syringe, the cooling bath was removed and the mixture was allowed to reach room temperature. An aq. saturated $\mathrm{NH}_{4} \mathrm{Cl}$ solution was added (20 mL) and then the crude material was extracted with ether $(3 \times 15 \mathrm{~mL})$, dried over anhyd. $\mathrm{MgSO}_{4}$ and filtered. The solvent was removed in vacuo to give a yellow oil. The product (4.2 g, 93\%) was obtained as a yellow low -meting solid . TLC (silica gel, $20 \%$ ethyl acetate/hexanes $\mathrm{R}_{f}=0.46$ ); chromatographic purification ( 1 x $15 \mathrm{~cm}$, ethyl acetate/hexanes gradient); mp 34-35 ${ }^{\circ} \mathrm{C}$; IR ( $\mathrm{KBr}$, $\left.\mathrm{cm}^{-1}\right) 2933$ (s), 2854 (s), 1794 (s), 1753 (s), 1588 (s); ${ }^{1} \mathrm{H}$ NMR (CDCl, $\left.200 \mathrm{MHz}\right) \delta 5.41$ (sept, $J=6.2 \mathrm{~Hz}, 1 \mathrm{H}), 2.75$ (tt, $J=3.6,10.8 \mathrm{~Hz}, 1 \mathrm{H}), 1.93-1.85$ (m, 2H), 1.80-1.50 (m, 6H), 1.45 (d, $J$ $=6.2 \mathrm{~Hz}, 6 \mathrm{H}), 1.42-1.28(\mathrm{~m}, 2 \mathrm{H}) ;{ }^{13} \mathrm{C} \mathrm{NMR}\left(\mathrm{CDCl}_{3}, 75.5 \mathrm{MHz}\right) \delta 197.5,195.3,194.8,188.2$, 79.1, 36.5, 29.0, 25.7, 25.6, 23.0. Anal. Calcd. for $\mathrm{C}_{13} \mathrm{H}_{18} \mathrm{O}_{3}$ : C, 70.24; H, 8.16. Found: C, 70.15; H, 8.33.

2-Cyclohexyl-3-isopropoxy-4-hydroxy-4-phenyl-2-cyclobuten-1-one (4). Phenyllithium (3.96 mmol) was added via syringe to a cold $\left(-78{ }^{\circ} \mathrm{C}\right)$ THF $(10 \mathrm{~mL})$ solution of dione 2 (0.8 $\mathrm{g}, 3.6$ mmol). The mixture was stirred at that temperature for four hours after which, it was quenched with an aq. saturated $\mathrm{NH}_{4} \mathrm{Cl}$ solution $(15 \mathrm{~mL})$. The cooling bath was removed and the mixture was allowed to reach room temperature. It was then extracted with ether $(3 \mathrm{x} 15 \mathrm{~mL})$, dried (anhyd. $\left.\mathrm{MgSO}_{4}\right)$, filtered and the solvent removed in vacuo. The product $(0.48 \mathrm{~g}, 44 \%)$ was obtained as a white solid. TLC (silica gel, 20\% ethyl acetate/hexanes $\mathrm{R}_{f}=0.22$ ); chromatographic purification ( 1 x $10 \mathrm{~cm}$, ethyl acetate/hexanes gradient) followed by trituration with hexanes; mp 125-127 ${ }^{\circ} \mathrm{C}$; IR (KBr, $\left.\mathrm{cm}^{-1}\right) 3163$ (m), 2980 (m), 2929 (m), 2850 (m), 1748 (s), 1607 (s); ${ }^{1} \mathrm{H}$ NMR $\left(\mathrm{CDCl}_{3}, 200 \mathrm{MHz}\right) \delta$ 7.52-7.22 (m, 5H), 4.64 (sept, $J=6.2 \mathrm{~Hz}, 1 \mathrm{H}$ ), 4.40 (bs, 1H), 2.32 (tt, $J=3.6,11.1 \mathrm{~Hz}, 1 \mathrm{H}), 1.90-1.49$ (m, $7 \mathrm{H}), 1.35$ (d, $J=6.2 \mathrm{~Hz}, 3 \mathrm{H}), 1.28$ (bs, 3H), 1.03 (d, $J=6.2 \mathrm{~Hz}, 3 \mathrm{H}) ;{ }^{13} \mathrm{C} \mathrm{NMR}\left(\mathrm{CDCl}_{3}, 75.5 \mathrm{MHz}\right) \delta 190.0,180.5,137.5,133.8$, 128.7, 128.1, 125.7, 92.8, 78.1, 33.7, 30.5, 26.0, 23.0, 22.6. Anal. Calcd. for $\mathrm{C}_{19} \mathrm{H}_{24} \mathrm{O}_{3}$ : C, 75.97; H, 8.05. Found: C, 75.61; H, 8.35.

2-Cyclohexyl-3-isopropoxy-1,4-naphthoquinone (6). Enone 4 (0.45 g, $1.5 \mathrm{mmol}$ ) was placed in a round-bottomed flask and purged with nitrogen. The flask was then immersed in a preheated sand-bath at $135{ }^{\circ} \mathrm{C}$. After $45 \mathrm{~min}$, total conversion to hydroquinone 5 was observed (TLC silica gel, $20 \%$ ethyl acetate/hexanes $\mathrm{R}_{f}=0.59$ ). Then, the reaction flask was cooled down to ambient temperature and ether $(10 \mathrm{~mL})$ was added. The crude reaction mixture was stirred open to the air during $4 \mathrm{~h}$, after which all of $\mathbf{5}$ oxidized to $\mathbf{6}$. The solvent was removed in vacuo to yield a yellow oil. The product ( $0.35 \mathrm{~g}, 78 \%$ ) was obtained as a bright yellow oil. TLC (silica gel, 20\% ethyl acetate/hexanes $\left.\mathrm{R}_{f}=0.75\right)$; chromatographic purification ( $1 \mathrm{x} 12 \mathrm{~cm}$, ethyl acetate/hexanes gradient); IR (KBr, cm $\left.{ }^{-1}\right) 2926$ (m), 2852 (m), 1667 (s), 1596 (m), 1573 (m); ${ }^{1} \mathrm{H}$ NMR $\left(\mathrm{CDCl}_{3}\right.$, $200 \mathrm{MHz}) \delta 8.00-7.86(\mathrm{~m}, 2 \mathrm{H}), 7.68-7.50$ (m, 2H), 4.99 (sept, $J=6.2 \mathrm{~Hz}, 1 \mathrm{H}$ ), 3.05 (tt, $J=3.3$, $12.1 \mathrm{~Hz}, 1 \mathrm{H}), 1.99-1.20(\mathrm{~m}, 10 \mathrm{H}), 1.28(\mathrm{~d}, J=6.2 \mathrm{~Hz}, 6 \mathrm{H}) ;{ }^{13} \mathrm{C} \mathrm{NMR}\left(\mathrm{CDCl}_{3}, 75.5 \mathrm{MHz}\right) \delta$ 
185.2, 182.4, 156.8, 140.3, 133.8, 133.1, 132.7, 131.6, 126.4, 126.0, 76.0, 36.6, 30.2, 27.1, 26.2, 23.1..

Parvaquone (1). To a cold $\left(-78{ }^{\circ} \mathrm{C}\right)$ dichloromethane $(8 \mathrm{~mL})$ solution of naphthoquinone 6 (0.6 g, $2.0 \mathrm{mmol}$ ) was added dropwise a dichloromethane solution of $\mathrm{BBr}_{3}(4.5 \mathrm{~mL}, 4.5 \mathrm{mmol}, 1.0 \mathrm{M}$, 2.25 equiv). Once the addition was finished, the cooling bath was removed and the mixture was stirred for $40 \mathrm{~min}$ at room temperature. Then, water $(15 \mathrm{~mL})$ was added and the crude reaction mixture was stirred for $20 \mathrm{~min}$. The organic phase was then dried (anhyd $\mathrm{MgSO}_{4}$ ), and the solvent removed under reduced pressure. The product $(0.42 \mathrm{~g}, 81 \%)$ was obtained as a yellow solid. TLC (silica gel, $20 \%$ ethyl acetate/hexanes $\mathrm{R}_{f}=0.53$ ); chromatographic purification ( $1 \mathrm{x}$ $15 \mathrm{~cm}$, ethyl acetate/hexanes gradient); mp 133-135 ${ }^{\circ} \mathrm{C}$; IR (KBr, cm $\left.{ }^{-1}\right) 3353$ (s), 2926 (s), 1657 (s), 1385 (s); ${ }^{1} \mathrm{H}$ NMR $\left(\mathrm{CDCl}_{3}, 200 \mathrm{MHz}\right) \delta$ 8.16-8.02 (m, 2H), 7.80-7.60 (m, 2H), 7.43 (s, 1H), $3.07(\mathrm{tt}, J=3.5,12.1 \mathrm{~Hz}, 1 \mathrm{H}), 2.05-1.21(\mathrm{~m}, 10 \mathrm{H}) ;{ }^{13} \mathrm{C} \mathrm{NMR}\left(\mathrm{CDCl}_{3}, 75.5 \mathrm{MHz}\right) \delta 184.8$, 182.2, 153.0, 135.1, 133.4, 132.9, 129.4, 128.1, 127.1, 126.1, 35.3, 29.4, 26.9, 26.2. (Lit. ${ }^{4}$ ).

\section{Acknowledgements}

Funding from the University of Guanajuato is greatly appreciated. R. S-A. wishes to thank the University of Guanajuato for a scholarship. C. G. R-C wishes to thank the National Council of Science and Technology (Mexico) for a scholarship.

\section{References}

1 (a) The Chemistry of the Quinonoid Compounds, Patai, S.; Rappoport, Z., Ed. ; WileyInterscience: New York, 1988. (b) Spyroudis, S. Molecules 2000, 5, 1291. (c) Lima, N. M. F.; Correia, C. S.; Ferraz, P. A. L.; Pinto, A. V.; Pinto, M. C. R. F.; Santana, A. E. G.; Goulart, M. O. F. J. Braz. Chem. Soc. 2002, 13, 822.

2 Peña-Cabrera, E.; Liebeskind, L. S. J. Org. Chem. 2002, 67, 1689.

3 Yin, J.; Liebeskind, L. S. J. Org. Chem. 1998, 63, 5726 and references cited therein.

4 Harrity, J. P. A.; Kerr, W. J.; Middlemiss, D.; Scott, J. S. J. Organomet. Chem. 1997, 532, 219 and references cited therein.

5 (a) Moore, H. W.; Yerxa, B. R. In Synthetic Utility of Cyclobutendiones; Halton, B., Ed.; JAI Press: Greenwich, CT, 1995; Vol. 4, pp 81-162. (b) Liebeskind, L. S. Tetrahedron Symp. Print 1989, 45, 3053. (c). Koo, S.; Liebeskind, L. S. J. Am. Chem. Soc. 1995, 117, 3389. (d) Sun, L.; Liebeskind, L. S. J. Am. Chem. Soc. 1996, 118, 12473. (e) Paquette, L. A.; Doussot, P. Res. Chem. Intermed. 1996, 22, 767. (f) Ohno, M.; Yamamoto, Y.; Eguchi, S. Synlett 1998, 1167.

6 Liebeskind, L. S.; Fengl, R. W.; Wirtz, K. R.; Shawe, T. T. J. Org. Chem. 1988, 53, 2482. 
7 (a) Liebeskind, L. S. Tetrahedron 1989, 45, 3053, (b) Liebeskind, L. S.; Fengl, R. W.; Wirtz, K. R.; Shawe, T. T. J. Org. Chem. 1988, 53, 2482.

8 Foland, L. D.; Karlsson, J.O.; Perri, S. T.; Schwabe, R.; Xu, S. L.; Patil, S.; Moore, H. W. J. Am. Chem. Soc. 1989, 111, 975.

9 Baeckström, P.; Stridh, K.; Li, L.; Norin, T. Acta Chem. Scan. 1987, B41, 442. 